\title{
The meta-design of systems: how design, data and software enable the organizing of open, distributed, and collaborative processes
}

\author{
Menichinelli, Massimo \& Valsecchi, Francesca ${ }^{\mathrm{b}}$. \\ ${ }^{a}$ Department of Media, School of Art, Design and Architecture, Aalto University. Finland. \\ massimo.menichinelli@aalto.fi \\ ${ }^{\mathrm{b}}$ College of Design and Innovation, Tongji University, China. francesca@tongji.edu.cn
}

\begin{abstract}
The challenges posed by the complexity of our times requires the Design discipline to understand the many complex relationships behind the social, business, technology and territory dimensions of each project. Such nature of complex systems lays not only inside design projects, but also inside the design processes that generate them, and the ability of organizing them through meta-design approaches is becoming strategic. Since the turn of the century, the design discipline has increasingly moved its scope from single users to local and online communities, from isolated projects to system of solutions. This shift has brought researchers and practitioners to investigate tools and strategies to enable massscale interactions by adopting several models and tools coming from software development and web-based technologies: Open Source, P2P, DDD (Diffuse, Distributed, and Decentralized) systems. This influence has matured over the years, and if we observed in the past how such systemic models can be applied in the design practice (part 1), we are facing now a new phase where Design will have an increasing role in enabling such systems through the analysis, visualization and design of their collaborative tools, platforms, processes and organizations (part 2). This scope falls into the Meta-Design domain, where designers build environments for the collaborative design of open processes and their resulting organizations (part 3). In this paper, we address this phenomena by elaborating the Open Meta-Design framework (part 4), that provides a way for designing open, collaborative and distributed processes (including those in the professional design domain). The paper positions the framework among current meta-design and design approaches and develops its features of modeling, analysis, management and visualization of processes. This framework is based on four dimensions: conceptual (describing the philosophy, context and limitations of the approach), data (describing the ontology of design processes), design (visualizing designing processes) and software (managing the connections between the ontology and the visualization, the data and design dimensions). We believe that such a framework could potentially facilitate the participation and the creation of open, collaborative and distributed processes, enabling therefore more relevant interactions for communities. As a conclusion, the paper provides a roadmap for developing and testing the Open Meta-Design framework, and therefore evaluating its relevance in supporting complex projects (part 5).
\end{abstract}

Keywords: Open Design, Meta-Design, Design Process, Data Visualization, Organization 
The meta-design of systems: how design, data, software enable the organizing of open, distributed and collaborative processes.

\section{Introduction}

During the last century, the industries of manufacturing, commerce, distribution and design have been expanding their borders globally. At first through the slow evolution of industrial infrastructures and then rapidly since the last decades through connectivity enhancement and the service industry that is transforming management and organizations. Globalization has quickly eroded the borders of national economies by redistributing activities, business, and actors all over the world, while connecting them at the same time with ICT technologies.

This phenomenon has changed the nature of several economic - and to a larger extent also social and cultural - structures, and their consequent dependency to national laws: supply-chains and value-chains are increasingly distributed, opaque, and less and less under public understanding and control. Tools and approaches for mapping and understanding such distributed systems in an open and participatory way are therefore increasingly relevant. The rise in global communication capacity, and the distributed workflows had scaled-up the complexity of economy, its impact on a global scale, its sustainability risks; it also generated many possibilities to organize distributed collaborative processes that would benefit and affect also cultural, non-profit industries, and those initiatives that addressed global sustainability challenges.

By its connection with economic and management domains, the Design discipline is also being affected by this global changes. Design is increasingly focused on speculating and experimenting on the complex and systemic nature of projects, practices and issues to be addressed, in many different disciplinary streams. Through many approaches, the scope of design projects moves from single users to local and online communities, from isolated projects to system of solutions, reaching groups at a larger scale and within global domains. This shift has brought researchers and practitioners to investigate tools and strategies that enable mass-scale and remote interactions, by adopting several models coming from software development and web-based technologies: Open Source, P2P, DDD (Diffuse, Distributed, and Decentralized) systems. The integration of Design projects with large groups of users and of their localities has increased the level of complexity (or rather, the focus on the level of complexity) of the Design discipline not only inside design projects, but also inside the design processes that generate them, and the ability of organizing them, especially through meta-design approaches, is increasingly becoming strategic. Such direction is important for the management and visualization of the intangible aspects of design processes, and for the enabling of changes within the design processes and thanks to them through society and the economy.

In this paper, addressing the relationship between design and the action within complexity, we focus on the visualization challenge of meta-design: how you do represent a system, its relationships, the complexity of social and local dimensions, and at the same time how visualization can inform the design of meaningful complexity in within organizational, productive, and information structures. We will conclude providing a framework of practice for Design when dealing with: the visualization of complex systems, the participation to complex social interactions, the contextualization of projects in complex local systems, and the implementation of Open Source, P2P, DDD Systems.

The article provides a first an overview of Open Source, P2P, DDD systems and their application in design practice (part 2), an overview of existing meta-design approaches (part 3) and then propose the Open Meta-Design framework as the synthesis of these two domains (part 4).

The framework, named Open Meta-Design, enables designers to model, analyse, manage and visualize open, collaborative and distributed processes. It is composed by 1) conceptual dimension; 2) data format; 3) data visualization layout; 4) software guidelines. The proposed framework however needs experimentation, testing and refinement: therefore, as a conclusion, we highlight possible limitations in 
the Open Meta-Design proposal and we propose a possible roadmap for its further development and testing (part 5)

\section{Open source, P2P, Distributed, Decentralized,Systems, and Design}

Designers and design researchers have been increasingly interested in tools and strategies that can enable their interactions with larger groups of people distributed in several localities. This interest has especially focused on approaches coming from software development and web-based initiatives and technologies, like Open Source, P2P, Distributed, Diffuse and Decentralized (DDD) Systems. In the recent decades ICT technologies have shaped new ways of working, participating, and assessing projects, which in turn have contributed to shaping these technologies and adapt them to larger community of users and variety of cases. In fact, although the roots of online collaborative organizations of any kind can be traced to Free Software and Open Source first, and and P2P afterwards, these new technologies and their related organizational forms have been experimented not only within software and web domain, but basically in all the field of human creativity, music, biotechnology, movies, science, art, design and so on (Goetz 2003).

The variety of these implementations has been discussed and interpret through many theories, cases studies, and analytical framework, such as Web 2.0 (O'Reilly, 2005), Wikinomics (Tapscott \& Williams, 2010, 2006), Crowdsourcing (Howe, 2008, 2006), Collective Intelligence or Wisdom of the Crowds (Leadbeater, 2009; Levy, 1997; Shirky, 2011, 2008; Surowiecki, 2005), Peer Production (Benkler, 2002). Free / Open Source and P2P software were initially technological projects, but then innovateed critically the organizational level (Fogel, 2005; Weber, 2005), and time after time they became promising formats for the management of online, distributed, and community based activities.

For instances, since the new century Open Source principles and practices have been adopted outside the software industry (Goetz, 2003), and shaped large cultural phenomena such as the so called Open Source Everything (Steele, 2012). P2P dynamics have been generalized from software and adopted in many other contexts as well: the nodes in the network (devices, but also users, or any entities you may have as your network components) are not related to any central servers or middleman; this configuration has been considered a more efficient distribution model for a large variety of contents and flows (Benkler, 2002). Furthermore, many principles and guidelines based on P2P dynamics have been elaborated out of the scope of software applications as grounds for whole scenarios of sustainable future social structures (Bauwens, 2005; Kostakis \& Bauwens, 2014). All these models mostly refer to decentralized communications where each participant is a peer, where the work is based on shared assets and outcomes, and agency and work are distributed over networks. It is this property of diffuse, distributed and decentralized networks the central structure to the nature of bottom-up phenomena such as Open and $\mathrm{P} 2 \mathrm{P}$ systems; and they represent the broad framework we have to underst the formats of online massparticipation that have emerged in the past decades.

The relevance of Open, P2P and DDD systems with design discipline displays along two directions: 1) by embracing them in design practice, as collaborative and methodological tools at a local and global scale, or 2) by having them as objects of design, and applying design principles and creativity to their improvement and implementation. More recents examples of the first direction include Open Design cases (Abel et al., 2011; Ciuccarelli, 2008; Romano, 2015), which are especially linked to the emergence of the Distributed Manufacturing scenario (Bauwens, 2009) and of the Maker Movement (Anderson, 2012; Hatch, 2014): the collaboration around manufacturing technology is evolving around design projects developed collaboratively in a global community of Maker Laboratories - Fab Labs, 
The meta-design of systems: how design, data, software enable the organizing of open, distributed and collaborative processes.

Makerspaces, Hackerspaces and so on - that share traditional and digital manufacturing technologies (Abel et al., 2011; Anderson, 2012; Gershenfeld, 2005; Menichinelli, 2016).

On the second direction, design acts to enable and replicate such Open, P2P and DDD Systems through the analysis, visualization and implementation of their softwares, toolkits, platforms and collaborative processes and organization models. Examples as follow, cover the broad span of design outcomes: projects focusing on tools and components to support Open, P2P and DDD interactions such as OpenStructures (TEDx Talks, 2012), an open grid designed in order to facilitate the effective integration of several open projects into larger assemblies. As another case, P2P platforms have been designed to support interactions among participants - mostly in physical local contexts - and to offer comprehensive methodologies where the main design goal is to facilitate the emergence and growth of new network of participations (Cottam \& Leadbeater, 2004). Custom online platform have been designed to build global community of designers that produce open projects, contributing this way to innovative but notmainstream knowledge bases and organizational forms: a major example is OpenIDEO (Fuge \& Agogino, 2014), the online platform (coupled with a toolkit) developed by IDEO for the development of solution to global scale social challenges. Further in this direction, other approaches have integrated open and $\mathrm{p} 2 \mathrm{p}$ organizational forms feeding with the design practice in theOpen P2P Design framework (Menichinelli, 2006), and lastly introducing open and collaborative approaches to reflection and practice of meta-design in the Open Meta-Design framework (Menichinelli, 2015).

\section{Meta-Design for the design of open processes and organizations}

\subsection{Meta-Design: an overview}

The Design discipline adopts and learns from Open Source, P2P, DDD systems, it also builds and improves them, and designers can furthemore have a role in building environments for the collaborative design of open processes and their resulting organizations: we are particularly interested in reflecting and contributing to this cross-influence of Open Source, P2P, DDD systems and meta-design issues. In fact, in literature we found Meta-Design has been associated with many technologies which are now related with such systems - to mention: mass-customization, digital fabrication, generative design, open processes and the participation in online communities (Giaccardi, 2003). The technological variety has been crucial for the development of design processes and projects scaled and adequate to each community and their context.

Furthermore, Open Source, P2P, DDD systems and their integration with design bring new roles for both users and designers. The Design discipline has been discussing extensively about the integration of users in the design process, and elaborated many established approaches such as Participatory Design, UserCentered Design, User Experience Design and Co-Design (Rizzo, 2009). This literature offers many reflections about the meta-design practice. For example, Participatory Design implies a forecasting activity about how a design outcome will be used before it is designed, since this is also something that will be elaborate collectively through common design choices. Ehn (Ehn, 2008) identifies meta-design as a successful strategy to this design challenge, by considering it as a way to leave space for user participation in the design process even after the design concludes, suggesting the concept of 'designafter-design'. Also Fischer has valued the meta-design approach for its capacity to extend designed systems beyond their original nature, and because it includes the ongoing process in which stakeholders become co-designers. For Fischer, meta-design takes place not only at the time of design implementation, but throughout the whole existence of the system (Fischer \& Scharff, 2000). According to Fischer, Metadesign characterizes objectives, techniques, and processes for creating new media and environments that 
allow the owners of problems to act as designers. Within this perspective on meta-design, the activity of designing is more about generating the seeds for the emergence of projects, rather than carefully and precisely planning all the features and specifications (Fischer, 2003). He speculates about Meta-Design being more elaborate than User-Centered Design and Participatory Design because it shifts the control of the design process from designers to the hands of the users, embedding the action of 'designing the design process'; he ultimately acknowledge that "creating the technical and social conditions for broad participation in design activities is as important as creating the artifact itself" (Fischer \& Scharff, 2000), to the extent of elaborating a framework for understanding Meta-Design processes, known as "the Seeding, Evolutionary growth, Reseeding process model" (SER) (Fischer et al., 2009):

- Seeding: provide seeds that evolve over time through the small contributions of many people instead of complete systems.

- Evolutionary growth: a decentralized evolution of the seeds through use, exploration and extension by users.

- Reseeding: a deliberate, centralized effort to organize, formalize, and generalize solutions and artifacts created during evolutionary growth.

Being Meta-design a broad concept with different context of usage and understanding - extending from design to technology, society and biology - we here refers also especially to the broader overview offered by Giaccardi, who traces its roots, meanings and implications with a particular interest to creative industries (Giaccardi, 2003). Giaccardi considers Meta-Design an an emerging design culture more than an established design approach; it generates at the intersections of ICTs and Design, and to the extent, to Interaction Design and Net Art. The implications of "meta-" change the perspectives to designers from objects to process, from contents to structures; Giaccardi identifies three different declinations of MetaDesign, crossing etymological facts with extensive literature review: meta- as.

- behind (or designing design): "Design of Design processes" / "Design of the generative principle of forms" / "Design of the Design tools";

- with (or designing together): "Design of media and environments that allow users to act as designers" / "Design of the organization of flows";

- between/among (or designing the "in- between"): "Designing the spaces of participation" / "Design of relational settings and affective bodies".

The focus on evolutionary environments brought by Fischer and the cultural value that Giaccardi refers to meta-design both imply that design projects are not acts of planning of features and procedures to be implemented; they are instead the (creative) configuration of possibilities that will emerge from opening the mechanism of participation and manipulation. Both of these approaches to meta-design practice value grandly the property of emergence, that we learn from complex system being the ability of the individual components of a large system to coordinate actions together, and rising diverse productive behaviors; emergence happens when this coordination arises spontaneously from simple interactions among the parts, and include to consider their effect on the environment. This inspiration from the emergence property of complex systems would require meta-design propositions to support the process of continual adaptation of the project organization within an ever-changing environment. 
The meta-design of systems: how design, data, software enable the organizing of open, distributed and collaborative processes.

To say and favour that processes need to be emergent, however, is not to abandon all plans and structures, rather to make them open: an effective way to display complex processes is by focusing on creating effective opportunities for interaction. These rules ensure alignment among participants that increases the likelihood of emergent solutions leading to the intended goal, a phenomenon that is being studying as collective impact.

We contribute through this paper elaborating the Open Meta-Design framework, that provides a way for collaboratively design open, collaborative and distributed processes (including both the professional design domain and the amateur design domain), and that embraces this proposition of facilitating interactions and stimulate unplanned changes on the design environment. Implementing an open approach to meta-design strategies will more favourably generate design projects that can adapt and scale to each specific context, its constraints and requirements, and therefore will facilitate organizations to adapt the process of collaboration to their own configurations of actors, places and networks.

\subsection{Tools for Process Design and Meta-Design}

For the purpose of the design of design processes, Meta-Design has to adopt or create frameworks, tools, and methods, that allow to implement visualizations, analysis, modelling, managing, and controlling processes. Because of the aim of this paper to contribute a new framework outline for Open Meta-Design, and because of the interest in contextualizing the proposed framework among similar approaches, in this section we briefly cover the main existing frameworks in literature used to design processes, and compare them ( Table).

Table 1: Comparison of tools, frameworks and approaches for visualizing processes

\begin{tabular}{|c|c|c|c|c|c|}
\hline Family & Origin & Name & Focus & Understanding & Purpose \\
\hline $\begin{array}{l}\text { Engineering \& } \\
\text { Management }\end{array}$ & $\begin{array}{l}1910- \\
1915\end{array}$ & Gantt Chart & $\begin{array}{l}\text { Time } \\
\text { Dependencies }\end{array}$ & Intuitive & $\begin{array}{l}\text { Planning } \\
\text { Management }\end{array}$ \\
\hline $\begin{array}{l}\text { Engineering \& } \\
\text { Management }\end{array}$ & 1921 & $\begin{array}{l}\text { Gilbreth's Process } \\
\text { Chart / Flow Chart }\end{array}$ & $\begin{array}{l}\text { Logic } \\
\text { Tasks }\end{array}$ & Codified & $\begin{array}{l}\text { Planning } \\
\text { Management }\end{array}$ \\
\hline $\begin{array}{l}\text { Engineering \& } \\
\text { Management }\end{array}$ & $1950 \mathrm{~s}$ & $\begin{array}{l}\text { Functional Flow } \\
\text { Block Diagram } \\
(\text { FFBD) }\end{array}$ & $\begin{array}{l}\text { Logic } \\
\text { Tasks } \\
\text { Dependencies } \\
\text { Time } \\
\text { Network }\end{array}$ & Codified & $\begin{array}{l}\text { Planning } \\
\text { Management }\end{array}$ \\
\hline $\begin{array}{l}\text { Engineering \& } \\
\text { Management }\end{array}$ & 1957 & $\begin{array}{l}\text { Program } \\
\text { Evaluation and } \\
\text { Review Technique } \\
\text { (PERT) }\end{array}$ & $\begin{array}{l}\text { Logic } \\
\text { Time } \\
\text { Time needed } \\
\text { Tasks }\end{array}$ & Codified & $\begin{array}{l}\text { Planning } \\
\text { Management }\end{array}$ \\
\hline
\end{tabular}




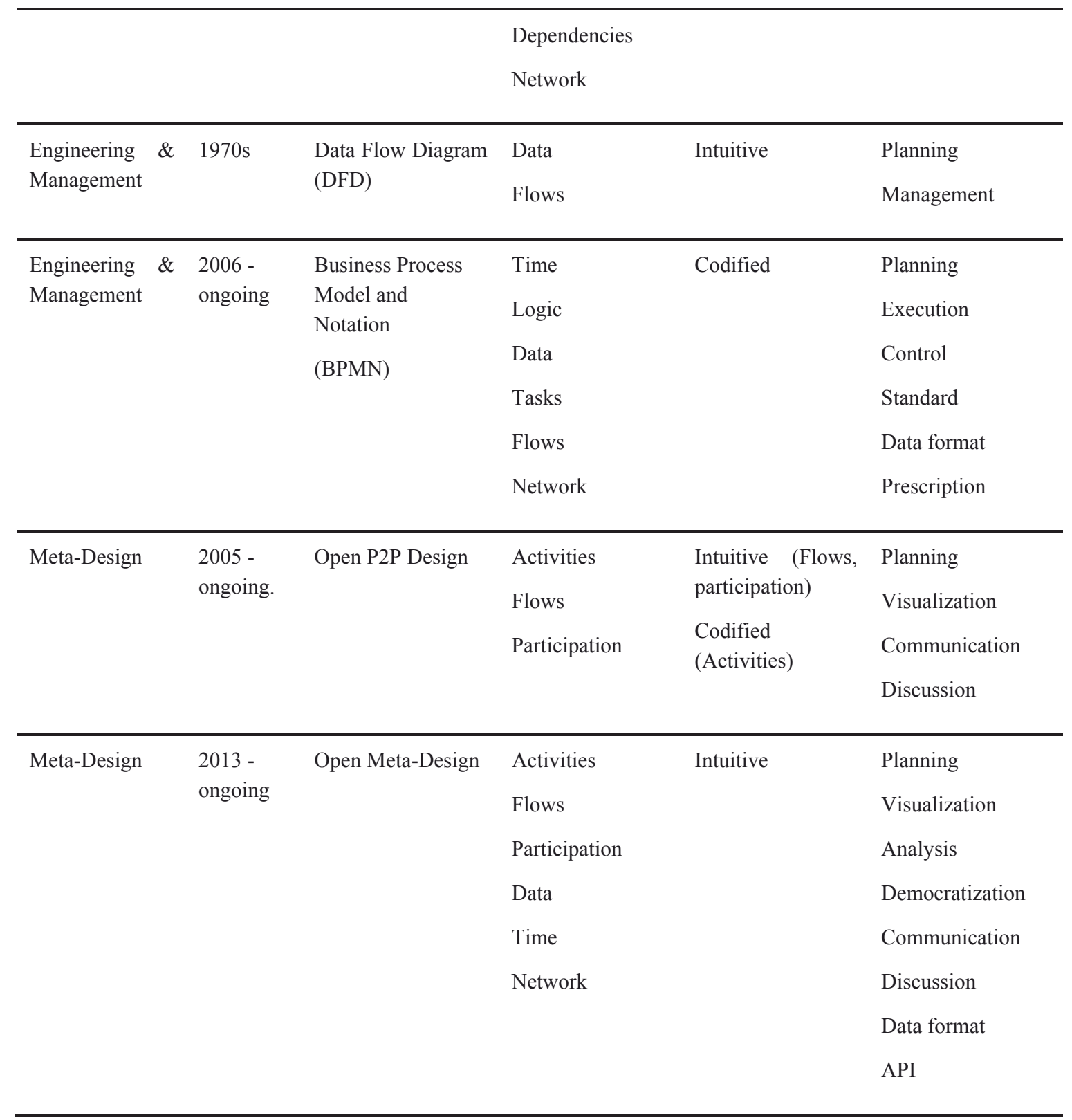

The development of such frameworks emerged with scientific management, proceeded with large engineering and military efforts, then embraced also information and computing disciplines with the introduction of digital technologies, and recently focused on the standardization of data formats, visualization and execution tools (Henrink von Scheel et al., 2015: 2). Henry Laurence Gantt developed his methodology and the Gantt Chart while working for Frederick W. Taylor in the realization of major infrastructure projects. Frank B. Gilbreth was studying and documenting the movements associated with physical labor, and implemented Process Charts to reduce them and make the flow of the process more efficient. In 1947, the American Society of Mechanical Engineers (ASME) became the first organization to develop and establish an international standard of process symbols by extending Gilbreth's work. Functional Flow Block Diagrams (FFBD) were introduced in the 1950s to describe production environment as systems, by showing the sequential relations between all the functions. Later, the introduction of PERT methodology changed the use of timelines by adding the estimation of necessary 

processes.

times and possible delays. The Data Flow Diagram was instead introduced in order to enable the visualization of where information (data) is stored, and how inputs, outputs and flows of information are organized in the process among the tasks.

In the 2000s, the Business Process Model and Notation (BPMN) emerged as a standard for graphical notation by extending previous flowchart techniques, with the goal to ensure that BPMN models can be executable through a machine-readable XML data format. The standard and its specification are currently at the third draft (1.0 in 2004, 1.1 in 2008, and 2.0 in 2011). BPMN focuses on process and it is not therefore comprehensive; for example several authors note that it does not attempt to model organizations and strategic direction: for example, it does not cover the relation between organizational structures, including business competencies, capabilities, and resources to processes (Henrik von Scheel et al., 2015).

Through the decades, several framework have been developed with ontology more appropriated to processes, improved elements for its graphical notation, integrated softwares.

Despite the large case study value, most of these approaches from engineering and management domain mainly consider processes as business processes: "a collection of tasks and activities (business operations and actions) consisting of employees, materials, machines, systems, and methods that are being structured in such way as to design, create, and deliver a product or a service to the consumer" (Henrik von Scheel et al., 2015: 1); moreover, in such frameworks, graphical notation is much more than intuitive, and therefore they are mainly accessible only to stakeholders already trained or used to business settings. These might be relevant limitations for their adoption in Open and P2P systems, based on a potentially large participation of users with a different background and which which may not always be a driven by business relations and values.

A first attempt at building a bridge between meta-design and business process modeling has been done by Selim Erol, whose research focused on applying meta-design guidelines from Fischer (Fischer et al., 2009) to BPMN. Erol noticed that research on business processes has mainly focused on creating flexible process modeling techniques, and workflow management systems, rather than on the flexibility and openness of modeling environments, especially to enable end-user or diverse and unplanned stakeholders participation in modeling. Furthermore, typical process modeling follows a linear model limited to design-time, and where requirements are previously defined (Erol et al., 2010). He therefore developed and tested a flexible and open wiki-based BPMN meta-design modeling environment called xoProcessWiki (Erol, 2012): the environment proved to be very useful but at the same time it showed a strong need for instruction and facilitation during the modeling process, showing the limitation in largescale adoption, and missing function of evaluation and assessments.

In the last decade, a more direct connection between meta-design and Open, P2P and DDD Systems has been investigated outside of the business domain by the two frameworks of Open P2P Design, and its derived Open Meta-Design: these frameworks are oriented to collaborative processes generated by communities and deployed within their social networks. The Open P2P Design approach develops at the intersection between Service Design, Activity Theory, and Participatory Urbanism and focuses on communities and their open and p2p processes, meaning networks of activities with different levels of participation (Menichinelli, 2011, 2006). It is mainly based on open methodologies and toolkits for modeling processes, which are shared with the community the process is intended for. Open P2P Design have been experimented in a series of short workshops about Open Design and Distributed Manufacturing, where it proved to be promising but with limitations in the lack of the time dimension in the visualization, an overtly complex description of activities, and the difficulty in working with several unrelated visualizations. These workshops pointed to the need of a simpler approach, an unified 
visualization in a single image or poster, and on the need for a framework for evaluating the real-life processes generated from the documentation of the designed processes. These results led to its simplification into the Open Meta-Design framework (FAD Barcelona, 2013; Menichinelli, 2015).

The Open Meta-Design framework is linked to Activity-centered Design (Gay \& Hembrooke, 2004; Kaptelinin \& Nardi, 2009); it defines that platform where collaborative communities can act are more than online services, they are instead network-based architecture that support also online services by shared productive components within the social network of the participants, such as artifacts, rules and roles. Having activity as its core goal, Open Meta-Design aims to clear communication, to produce easy visualization, to offer integrated tool and data format and the versatility to more generic domain of application. Implementing Meta-Design principles and the properties of Open, P2P and DDD Systems for the facilitation of socio-technical communities can be useful to benefit their openness, adaptability to local conditions and emergent behaviours. Such approaches should be intuitive and not restricted to professionals only, should have a clear data strategy that enables tools, functionalities and data interchange, and should provide the function of development assessment.

We believe the Open Meta-Design will be promisingly explored with further research and practice; however it is still a very recent framework who is lacking complete formulation in current literature. For this reason, in the next section we contribute to elaborate its structure, which is based on:

1. A contextual description of Open Meta-Design within the lifecycle of projects and their organizations;

2. A data format that describes a process ontology, and it represents the basic layer for a tool for collaborative design;

3. A visualization format that renders the data format in an intuitive way;

4. A software layer which binds together data, visualization, graphical user interface and collaborative editing, being this one the interface of production.

\section{Open Meta-Design: a proposal for a meta-design framework along four dimensions}

\subsection{The conceptual dimension of Open Meta-Design}

The main concept of Open Meta-Design is that designers and stakeholders can work together as network of peers in defining the process and the methods of their collaborative activities. The meta-design component refer to the design of a tool that enables stakeholders to collaboratively design processes in online environment where they can discuss their participation. The open component focuses on the open source and $\mathrm{p} 2 \mathrm{p}$ features of the relationships that are generated and of the projects that are developed. The roots of Open Meta-Design for both concepts and tools can be traced in the Open P2P Design framework along three directions:

- Cultural-historical Activity Theory (CHAT): a framework that focuses on studying work and organizations, analysed through the model of Activity System which enables a complex overview of the mediational structure of the activities, the contradictions within activities and among activities as critical issues but also potential paths for development, since activities incessantly reconstruct themselves (Engestrom, 1987). An activity-centered approach focuses 

processes.

also more on how tools mediate activities among multiple actors, and is therefore more apt to the meta-design of a process where multiple actors interact.

- Service Design: a design discipline dedicated to the planning of services between providers and customers with a focus on both immaterial interactions and flows among people, infrastructures, organizations, and on physical touch-points in space, artifacts, interfaces. The Service Design community has developed several tools useful to map the interactions and flows among people, spaces and artifacts (Alves \& Nunes, 2013; Tassi, 2008) that can be adopted for Meta-Design. Furthermore, some approaches tried to adopt Activity Theory in Service Design as reference model for service evaluation thanks to its systemic, social and artefact-mediated conception of activity and are therefore promising for meta-design processes (Maffei \& Sangiorgi, 2006; Sangiorgi, 2004).

Studies on the structure and classification of participation: several researchers and practitioners pointed out that participation is not just a final goal, but also an intermediate tool for structuring design processes and that there are different levels of participation of stakeholders (Arnstein, 1969; Friedman \& Miles, 2006; Hamdi \& Goethert, 1997). Participation is not always uniform and tota: these approaches can be considered as a tool for shaping the amount and quality of participation in processes; the participation matrix is an example in this direction (Hamdi \& Goethert, 1997).

These directions outline an implementation scenario of Open Meta-Design approach, compliant to the classification of meta-design from Giaccardi (Giaccardi):

1. behind (or designing design): Open Meta-Design is a framework of design tools that generate the design of processes;

2. with (or designing together): Open Meta-Design is a framework with an online environment and a data format that allow users to design the organization of flows;

3. between/among (or designing the "in-between"): Open Meta-Design is a framework for collaboratively designing the organization of participation in processes through an open discussion.

Furthermore, the Open Meta-Design framework offers a new model for how phases of the project are organized over time.(figure 1). Any design process (intended as the development of human-made artifacts) undergo two basic stages: design time and use time. (Fischer 2009) ( Figure A). When a metadesign approach focuses only on design tools and processes, it tends to take place at the beginning of such generic processes, befor design time (Figure B). When a meta-design approach focuses on the development of an interactive environment, this approach last for all the life of a project since the environment sustains it ( Figure C). In the Open Meta-Design framework instead, the meta-design approach precedes all the other phases, and beside design time and use time it includes production (which is increasingly important in Open Design projects and in new initiatives with many non-professionals), distribution, and project life cycle, and possible future projects time that is the case when the project is open source. 
(A)

A generic design process without meta-design Design Time Use Time

(B)

A design process started by meta-design (meta-design as tools)

Meta-Design Design Time Use Time

A design process enabled by meta-design (meta-design as interactive environments)

(C)

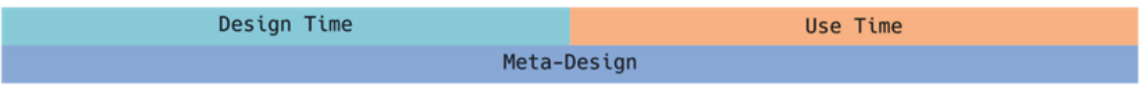

An Open Meta-Design process

(D)
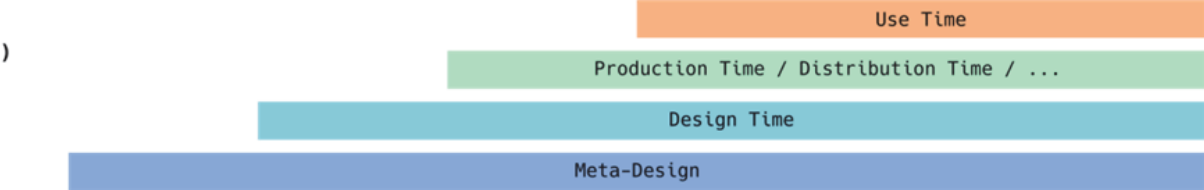

Time

Fig. 1: Time and activities in Open Meta-Design process compared to other conventional design processes

The Open Meta-Design framework has been developed as a more general version of the Open P2P Design framework, making its application broader. As any framework, it cannot encompass all the complexity of sociotechnical systems, therefore it is important to understand its limitations. The framework is thought for developing processes, but these are part of a larger system: when they are implemented, they generate social interactions and therefore social networks; these networks give place to organizations for the management of their social dimension; such organizations then bring governance structures and rules for the management of the system, and the governance influences the processes and their design ( Figure).

The Open Meta-Design framework has then a specific and limited place in the life cycle of the social and organizational dimension of the projects it enables, and other approaches might be coupled to it in order to improve all the aspects of its life cycle: social network analysis for understanding the networks, visualization and other techniques for making the organization visibles, conflict management for facilitating the governance. All these approaches can be implemented in Open Meta-Design platforms with time, extending the design of processes to a complete management of collaborative systems. 
The meta-design of systems: how design, data, software enable the organizing of open, distributed and collaborative processes.

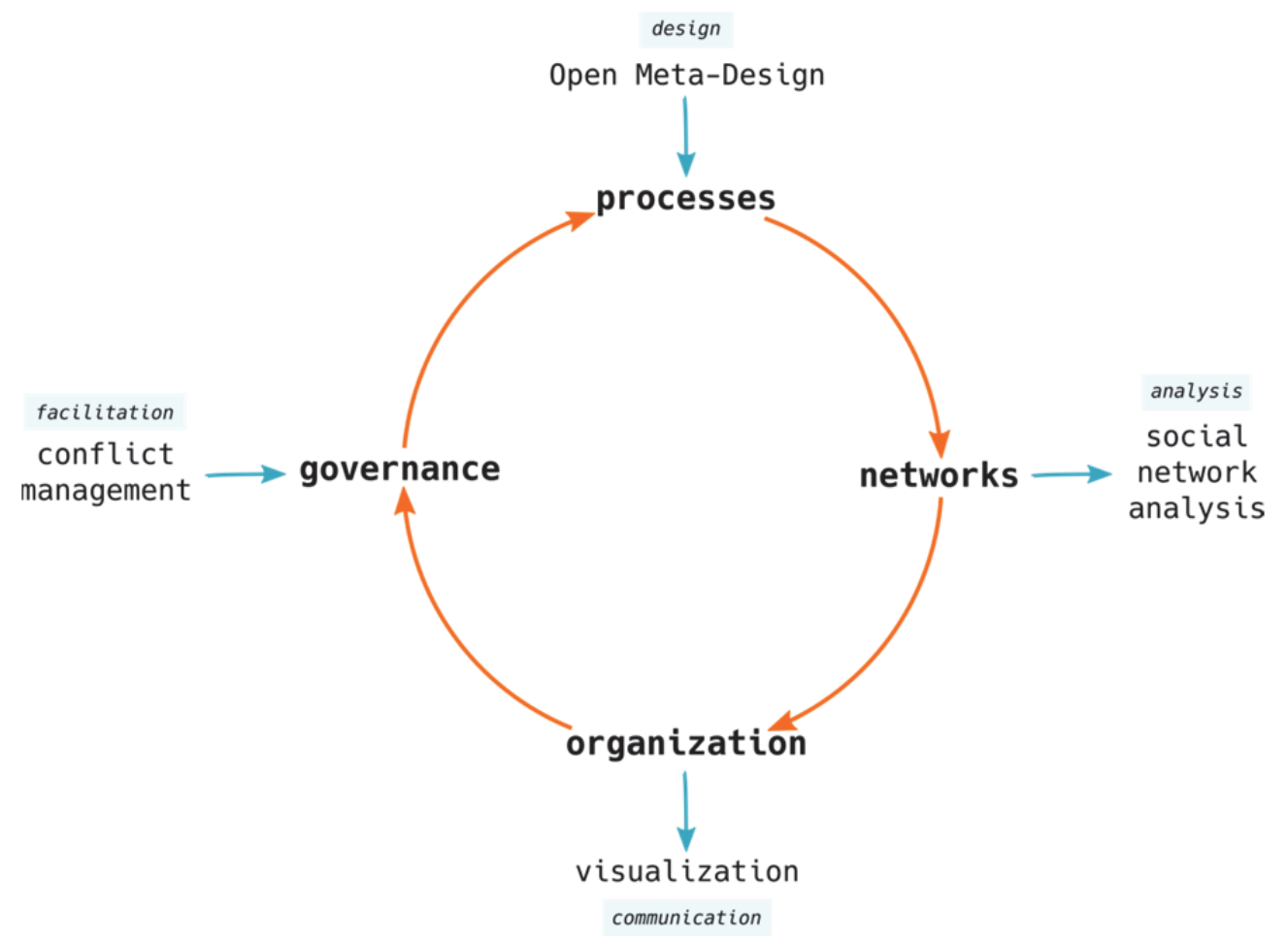

Fig. 2: The role of Open Meta-Design in the life cycle of the social and organizational dimension of a project

\subsection{The data dimension of an Open Meta-Design ontology}

A custom data format that store a specific process ontology is needed in order to enable the development of an interactive environment for design, discussion and sharing, The data dimension and the design dimension of the following section have been designed in parallel way with multiple feedback loops between them. In this case therefore, the ontology has been designed from the bottom-up, re-elaborating previous tools and experiences into a single tool, multiple sources of data into a single data format. The data is managed by a software dimensione (section 4.4) that connects it to the design visualization and that manages its sharing, accessibility and export: for an online platform, the implementation of custom APIs can manage the access to the data through different file formats. For these reasons, the data ontology has been structured from the bottom-up starting with software code, from which a graphical representation in UML has been automatically generated ( Figure). After this iterative design phase, the results point out how Location (online or offline) is the starting point of a process, from which Time Intervals, Persons and Activity Elements generate. Activity Elements constitute together Activities, which are linked by Flows into Processes and by Contradictions into a Discussions (based on single items called Issues to mirror the collective discussion in open source projects on platforms like GitHub) among the participants in the meta-design project. More Processes constitute an Open Meta-Design Project, which is shared through a License that governs its IP. Activities and the flows among them constitute processes, activities and contradictions among them and in them generate discussions, and discussions and processes constitute Open Meta-Design projects. 


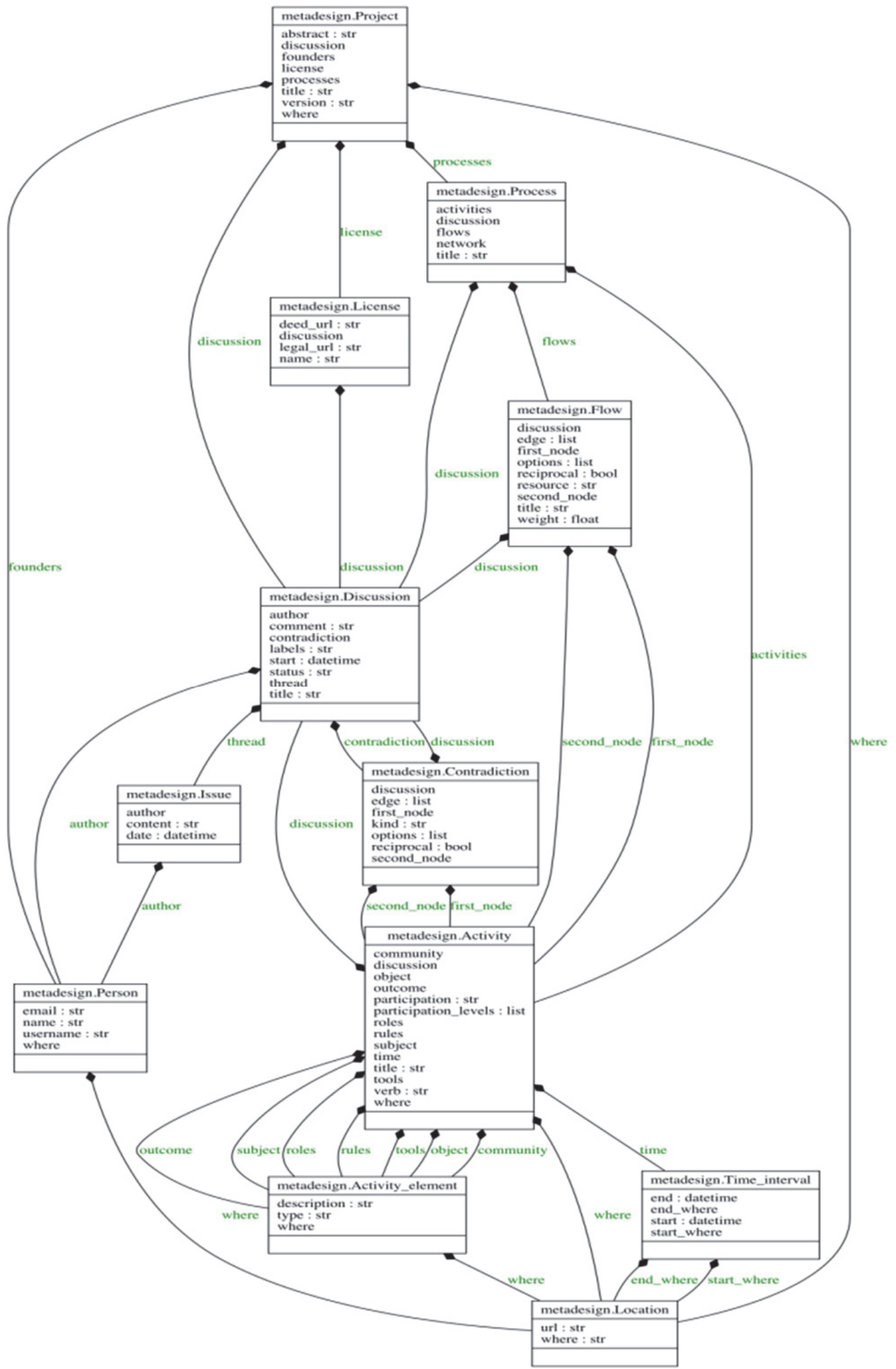

Fig 1: A preliminary UML visualization of the classes describing the data structure of an Open Meta-Design project. 
The meta-design of systems: how design, data, software enable the organizing of open, distributed and collaborative processes.

\subsection{The design dimension of an Open Meta-Design tool}

The first proposal of the design dimension of Open Meta-Design (Figure 3) has been developed during several iterations together with the data ontology, since they are interconnected: processes are visualized by the design dimension that renders the data and the data dimension describes the design of processes which are designed on the platform or environment. Furthermore, it integrates the various design tools tested within the Open P2P Design framework in one single visualization, and tries to simplify the more complex tools (Menichinelli, 2015). The workshops where the Open P2P Design framework was tested showed in fact that one single visualization would have been more understandable and easy to use, and that activities were too complex to be designed and analysed with Activity Theory by untrained users. Furthermore, the time element was missing or poorly implemented. For these reasons, some of the tools adopted by Open P2P Design (System Map, Participation Matrix) are now integrated in one single visualization where time is represented and managed like in Gantt charts and where activities are represented in a textual way in order to make it easier for the users to understand them. The Activity System is a powerful framework for understanding and designing activities, but its visualization is not very useful to untrained users. Therefore, the Activity Systems are here represented as a short text scripts that explain their structure and help the users to edit them. Activities are then grouped by similarity in processes. The script analogy has been also adopted for the title and a short description of the main project at the top / beginning of the visualization. The use of the script metaphor could be useful then for obtaining a clear representation of complex and intangible activities, and it could also be useful for their data analysis. The text as an interface for complex systems, that could be analysed and visualised later with a global overview of all the activities. Movies script have been adopted for data analysis and visualization several times; an interesting example can be found in the Star Wars movies, which have been at first depicted in a hand-drawn chart on the XCKD website (Munroe, 2009). The popularity of this visualization has lead data scientists and designers to develop software for automatising the analysis and visualization of such scripts as processes (Franklin et al., 2015), but also for understanding their social networks (Gabasova, 2016, 2015) and activities and performance (Diamond et al., 2015). From a single script (or shorter scripts) it is therefore possible to analyse and visualize complex processes and activities.

Contradictions and flows are instead represented as connections between different scripts or elements of the scripts, in order to show the systemic nature of processes generated by several activities. Furthermore, a preliminary study of a possible integration of the design dimension with a GUI for an online platform has led to the integration of elements for user interaction (the orange elements in Figure). 


\section{Title of the project $\bullet \bullet$}

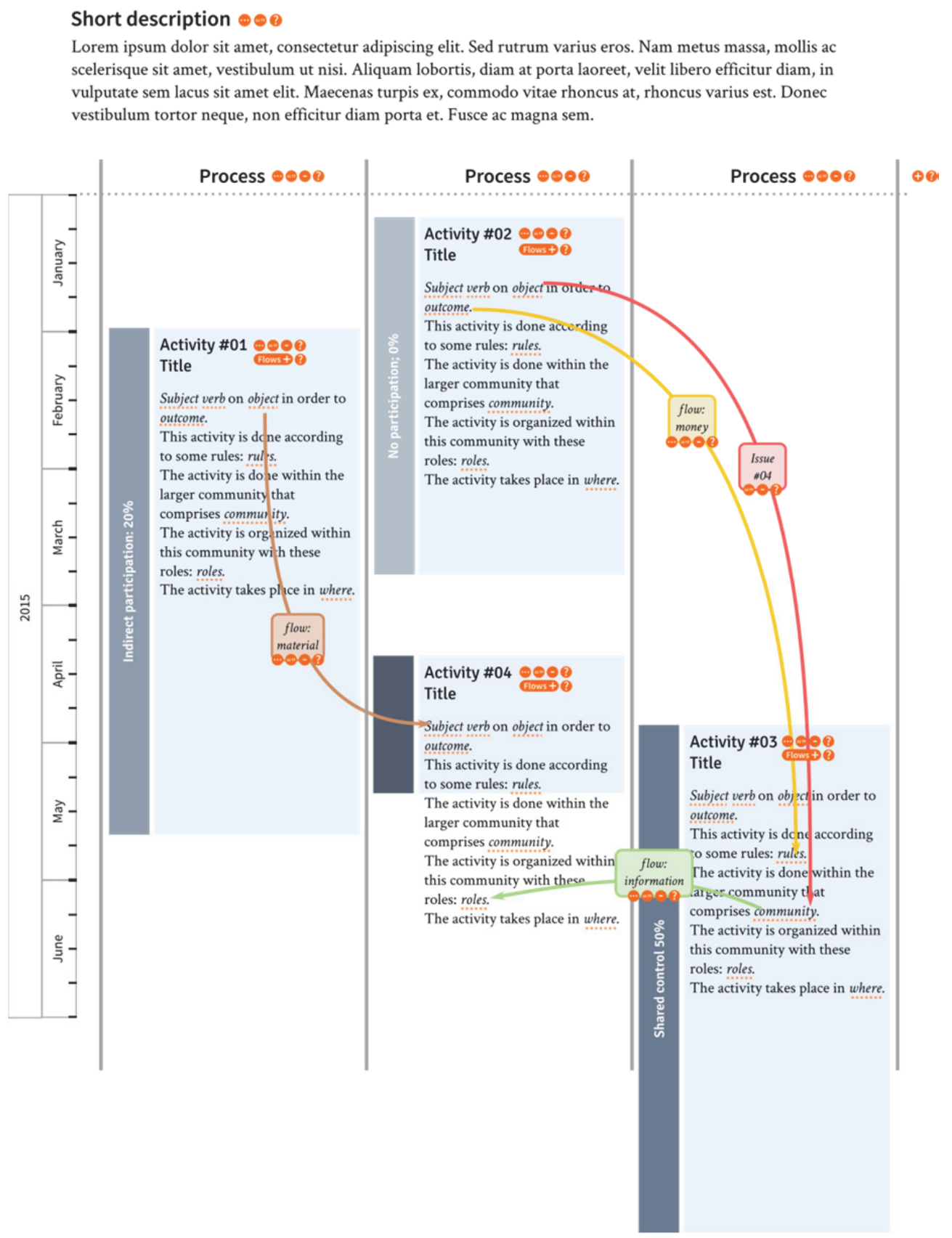

Fig. 4: A proposal for an Open Meta-Design visualization tool and interface

\subsection{The software dimension of an Open Meta-Design tool}

The conceptual dimension clarifies the position of Open Meta-Design within design, analysis and metadesign approaches and within the life cycle of the organizations behind projects. The data dimension describes the ontology of projects as processes built from networks of activities. The design dimension renders the ontology and enables the users to understand it and design it. These dimensions could be 
The meta-design of systems: how design, data, software enable the organizing of open, distributed and collaborative processes.

implemented with analog tools like a paper toolkit as in the Business Model Canvas (Osterwalder \& Pigneur, 2010), but we think that the complexity of socio-technical systems could be facilitated with more flexibility and scalability with digital platforms and data. In this direction, the software dimension of Open Meta-Design would represent the common layer that binds together the data, design and user interface dimensions. Such layer would enable the collaborative editing of processes by multiple users, the sharing and accessibility of projects, the interfacing and application of meta-design approaches to other platforms and therefore contexts as well. For example, the UML visualization of the data structure ( Figure) was already automatically generated from software code. Such a dimension would require extensive development, but for the scope of this proposal we identify some design guidelines, following the example of Erol (Erol et al., 2010) that defined the guidelines for the xoProcessWiki platform according to Fischer's guidelines for meta-design environments and software systems (Fischer et al., 2009)( Table).

Table 2: Key features of an Open Meta-Design software platform derived from (Fischer 2009)

\begin{tabular}{ll}
\hline Meta-Design guidelines (Fischer et al., 2009) & Related key features to be implemented in software \\
\hline 1. Support Human-Problem Interaction & GUI for collaborative design \\
& $\begin{array}{l}\text { Clear explanations or tours of the GUI and the } \\
\text { visualization }\end{array}$ \\
Open APIs and libraries for developers \\
\hline
\end{tabular}

2. Underdesign for Emergent Behavior Empty or half-empty templates of projects

3. Enable Legitimate Peripheral Participation Discussion with issues

Analyse and visualize the contribution of participants

Analyse and visualize the reputation obtained by participants

4. Share Control Data export

Open APIs

Open source software and libraries
5. Promote Mutual Learning and Support
Discussion

6. Reward and Recognize Contributions

Document motivations in discussions

Analyse and visualise contributions in the discussion

7. Foster Reflective Communities

Describe the background and expertise of each
participant

Foster the collaboration and sharing among participants with different background and expertise 


\section{Conclusions}

The increasing complexity brought by globalization and by the quest for sustainability in society and the economy might find suitable approaches in the increasing involvement of all stakeholders in the design processes and in the management of such processes. Open, P2P and DDD Systems could represent a promising direction for enabling the participation of a potentially large pool of distributed users in design processes. These systems however brings also new organizational forms and new principles and practices, making their design not a straightforward task. Stakeholders could be therefore involved in the definition of such systems and of their processes, and meta-design approaches could be useful for enabling designers to have a role in the definition and management of such systems and processes. Existing frameworks and tools for designing, managing or meta-designing processes are complex to use for nonprofessionals or incomplete: for this reason we propose the Open Meta-Design framework in this article. The framework represents a bridge between design, meta-design, social sciences, computer science. Compared to previous frameworks like Open P2P Design, this framework provides a more structured approach, based on the modeling, analysis, management and visualization of open, collaborative and distributed processes. This framework is based four dimensions: concept (describing the philosophy, context and limitations of the approach), data (describing the ontology of design processes), design (visualizing designing processes) and software (managing the connections between the ontology and the visualization, the data and design dimensions). Such approach and framework could potentially lower the barriers to the participation in the design and discussion of open, collaborative and distributed processes, enabling therefore mass-scale interactions and a new role for designers, based on an augmented awareness of the possibilities of design processes and organizations.

The proposal is still preliminary, and a complete implementation and testing is needed in order to understand its viability. More dimensions, domains, features or tools could be added but this direction requires a careful consideration in order to balance the trade-off between ease of use and complexity. Since most of the process design frameworks focused only on business processes, the current proposal does not include a business dimension. This could be a critical limitation, given the fact that even collaborative processes needs to reach a sustainability in order to proceed with their activities. Furthermore, a final implementation in an online platform for example, could show more critical issues and missing elements. As a conclusion, we suggest a roadmap for developing and testing the Open MetaDesign framework, and therefore evaluating its relevance in supporting complex projects. The conceptual dimension of the framework ( Figure) could represent not only a way for understanding its limitations, but also a way for testing it and developing it further. For this reason, we suggest that the impact of such framework could be analysed along the dimensions of networks, organization and governance. However, the conceptual dimension could need further refinement in order to constitute a complete evaluation framework for the testing of Open Meta-Design. The next steps in this direction could be: 1) implement and refine the framework within an online platform; 2) test the platform: the adoption of the same or similar context of the testing of the Open P2P Design framework could provide a useful reference; 3 ) dissemination of results, tools and documentation for the replication and diffusion of the framework through its platforms or similarly related platforms. 
The meta-design of systems: how design, data, software enable the organizing of open, distributed and collaborative processes.

\section{References}

ABEL, B., EVERS, L., KLAASSEN, R. \& TROXLER, P. (2011). OPEN DESIGN Now : WHY DESIGN CANNOT REMAIN EXCLUSIVE. AMSTERDAM: BIS PuBliSHERS <HTTP://OPENDESIGNNOW.oRG/> [ACCESSED: MAY 15, 2016].

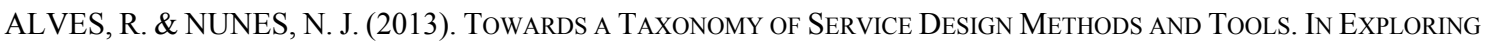
SERVICES SCIENCE, PP. 215-229. SPRINGER < HTTP://LINK.SPRINGER.COM/CHAPTER/10.1007/978-3-642-36356-6_16> [ACCESSED DECEMBER 27, 2014].

ANDERSON, C. (2012). MAKERS: The New Industrial Revolution. New York: Crown Business.

ARNSTEIN, S. R. (1969). A LADDER OF CITIZEN PARTICIPATION. JOURNAL OF THE AMERICAN INSTITUTE OF PLANNERS 35, 216-224. <HTTP://WWW.TANDFONLINE.COM/DOI/ABS/10.1080/01944366908977225> [ACCESSED NOVEMBER 7, 2013].

BAUWENS, M. (2005). P2P AND Human EVOlution: PEer TO PEER AS THE PREMiSE OF A NEW MOde OF CiVILIZATION. ESSAY 1. <HTTP://LIBRARY.UNITEDDIVERSITY.COOP/MONEY_AND_ECONOMICS/P2P_ESSAY.PDF> [ACCESSED DECEMBER $30,2015]$.

(2009). The Emergence of Open Design and Open Manufacturing. We_Magazine < http://Www.weMAGAZINE.NET/WE-VOLUME-02/> [ACCESSED: 15TH OF MAY 2016].

BenKleR, Y. (2002). Coase's Penguin, Or, Linux and The Nature of the Firm. The Yale Law Journal 112. <HTTP://WWW.YALELAWJOURNAL.ORG/THE-YALE-LAW-JOURNAL/CONTENT-PAGES/COASE\%27S-PENGUIN,-OR,-LINUXAND-THE-NATURE-OF-THE-FIRM/> [ACCESSED JUNE 9, 2010].

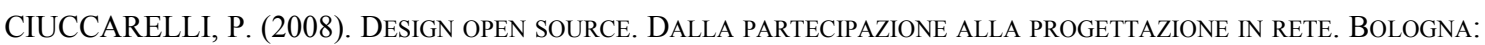
PITAGORA EDITRICE.

COTTAM, H. \& LEADBEATER, C. (2004). RED PAPER 01: Health. Design Council <HTTP://WWW.DESIGNCOUNCIL.ORG.UK/RESOURCES/REPORT/RED-PAPER-01-HEALTH> [ACCESSED MAY 31, 2010].

DiAmond, J. S., GLASSMAN, M., Illick, C. \& Whiteaker, C. (2015). Star Wars: The Force Accounted. BLOOMBERG.COM. <HTTP://WwW.BLOOMBERG.COM/GRAPHICS/2015-STAR-WARS-THE-FORCE-ACCOUNTED/> [ACCESSED MAY 12, 2016].

EHN, P. (2008). Participation In Design things. In ProceEdings of the Tenth AnNiVersary Conference on PARTICIPATORY DESIGN 2008, PDC '08, PP. 92-101. INDIANAPOLIS, IN, USA: INDIANA UNIVERSITY $<$ HTTP://DL.ACM.ORG/CITATION.CFM?ID=1795234.1795248> [ACCESSED OCTOBER 22, 2013].

ENGESTROM, Y. (1987). LEARNING BY EXPANDING: AN ACTIVITY-THEORETICAL APPROACH TO DEVELOPMENTAL RESEARCH. ORIENTA-KONSULTIT OY.

EROL, S. (2012). 'Design and Evaluation of A Wiki-Based Collaborative Process Modeling Environment'. DOCTORAL, WU VIENNA UNIVERSITY OF ECONOMICS AND BUSINESS < HTTP://EPUB.WU.AC.AT/3863/> [ACCESSED DECEMBER 28, 2014].

EROL, S., MÖDRITSCHER, F. \& NEUMANN, G. (2010). A MetA-Design APProaCh for Collaborative Process Modeling. In ProceEdings of the 2ND INTERNATIONAL WORKSHOP ON OPEN DESIGN SPACES (ODS 2010)VOL. 7. IISI - INTERNATIONAL INSTITUTE FOR SOCIO-INFORMATICS< HTTP://WWW.IISI.DE/INTERNATIONAL-REPORTS-ON-SOCIOINFORMATICS-IRSI/> [ACCESSED: MAY, 15 2016].

FAD BARCELONA (2013). Massimo Menichinelli - Process, Community, Business: The Systems Behind Open DESIGN. FAD BARCELONA <HTTPS://www.YOUTUBE.COM/wATCH? $\mathrm{v}=$ w8UUSZRTBPE $>$ [ACCESSED JANUARY 31, 2016].

FISCHER, G. (2003). META-DESIGN: BEYOND USER-CENTERED AND PARTICIPATORY DESIGN. IN PROCEEDINGS OF HCI INTERNATIONAL 2003, PP. 88-92.

FiSCHER, G., NAKAKOJI, K. \& Ye, Y. (2009). METAdeSign: GUIDELINES FOR SUPPORTING DOMAIN EXPERTS IN SOFTWARE DEVELOPMENT. SOFTWARE, IEEE 26, 37-44. <HTTP://L3D.CS.COLORADO.EDU/ GERHARD/PAPERS/2009IEEE-SOFTWARE.PDF> [ACCESSED MAY 15, 2016].

FISCHER, G. \& SCHARFF, E. (2000). META-DESIGN: DESIGN FOR DESIGNERS. In ProceEdings OF THE 3RD CONFERENCE ON DESIGNING INTERACTIVE SYSTEMS: PROCESSES, PRACTICES, METHODS, AND TECHNIQUES, PP. $396-405$. $<$ HTTP://L3D.CS.COLORADO.EDU/ GERHARD/PAPERS/DIS2000.PDF> [ACCESSED: MAY 15, 2016].

FOGEL, K. (2005). Producing Open Source Software: How to Run a Successful Free Software Project. 1St ed. Sebastopol: O’Reilly Media < HTtP://PROducingoss.COM/> [ACCESSED: MAy 15, 2016]. 
FRANKLIN, K., ELVERY, S. \& SPRAGGON, B. (2015). STAR WARS: EVERY SCENE FROM I-VI CHARTED. ABC NEWS. <HTTP://WWW.ABC.NET.AU/NEWS/2015-12-16/STAR-WARS-EVERY-SCENE/7013826> [ACCESSED JANUARY 20, 2016].

Friedman, A. L. \& MILES, S. (2006). Stakeholders: Theory and Practice. 1 edition. Oxford; New York: OXFORD UNIVERSITY PRESS.

Fuge, M. \& AGOGino, A. (2014). How Online Design Communities Evolve Over Time: the Birth AND Growth of OpenIDEO. In ASME 2014 InTERnATIONAL Design ENGINEERING TeChNicAl Conferences AND COMPUTERS AND INFORMATION IN ENGINEERING CONFERENCE, PP. V007T07A038-V007T07A038. AMERICAN SOCIETY OF MEChANICAL ENGINEERS < HTTP://IDEAL.UMD.EDU/PAPERS/FUGE_IDETC_2014_OI_EVOLUTION.PDF> [ACCESSED DECEMBER 31, 2015].

GABASOVA, E. (2015). The Star WARS SOCIAL NETWORK. Evelina Gabasova's Blog. <HTTP://EVELINAG.COM/BLOG/2015/12-15-STAR-WARS-SOCIAL-NETWORK/\#.VOGAQPMRJDA> [CCESSED JANUARY 2, 2016].

(2016). Star Wars social Networks: THE Force Awakens. Evelina Gabasova's BLOG.<HTTP://EVELINAG.COM/BLOG/2016/01-25-SOCIAL-NETWORK-FORCE-AWAKENS/INDEX.HTML\#.VZRHERV971I> [ACCESSED MAY 12, 2016].

GAY, G. \& HEMBrooke, H. (2004). Activity-Centered Design: An Ecological Approach to Designing SMART TOOLS AND USABLE SyStems. THE MIT PRESS.

GERSHENFELD, N. (2005). FAB: The Coming Revolution on Your DeskTop--From Personal Computers to PERSONAL FABRICATION. NEW York: BASIC BOOKS.

GiacCARDi, E. (2003). 'Principles of Metadesign: Processes and Levels of Co-Creation in the New Design SPACE'. DOCTORAL DisSERTATION, PlyMOUTH: UNIVERSiTy OF PLYMOUTH <HTTPS://PEARL.PLYMOUTH.AC.UK/HANDLE/10026.1/799> [ACCESSED OCTOBER 24, 2011].

GOETZ, T. (2003). OPEN SOURCE EVERYWHERE. WirED, NOVMBER <HTTP://WWW.WIRED.COM/WIRED/ARCHIVE/11.11/OPENSOURCE.HTML>[ACCESSED: MAY 15, 2016].

HAMDI, N. \& GOETHERT, R. (1997). ACTION PLANNING FOR CITIES : A GUIDE TO COMMUNITY PRACTICE / NABEEL HAMdi AND ReinHARd GOETHERT. CHICHESTER ETC: JOHN WILEY.

HATCH, M. (2014). THE MAKER MOVEMENT MANIFESTO. RULES FOR INNOVATION IN THE NEW WORLD OF CRAFTERS, HACKERS, AND TINKERERS. NEW YORK: MCGRAW-HILL EDUCATION.

HOWE, J. (2006). THE RISE OF CROWDSOURCING. WIRED, JUNE <HTTP://WWW.WIRED.COM/WIRED/ARCHIVE/14.06/CROWDS.HTML> [ACCESSED: MAY 15, 2016].

(2008). Crowdsourcing: Why the Power of the Crowd Is Driving the Future of Business. 1st ed. CROWN BUSINESS.

Kaptelinin, V. \& Nardi, B. A. (2009). Acting with Technology: Activity Theory and Interaction Design. THE MIT PRESS.

Kostakis, V. \& Bauwens, M. (2014). Network Society and Future Scenarios for a Collaborative Economy. 2014 EDITION. BASINGSTOKE: PALgRAVE PiVOT.

Leadbeater, C. (2009). We-Think: Mass inNovation, not MASS Production. 2ND ED. Profile Books.

LeVy, P. (1997). Collective InTElligence: MANKind’s EMERging World in Cyberspace. 1st edition. NeW York: Plenum TRAde.

Maffei, S. \& SAngiorgi, D. (2006). From communication design to activity design. In Designing Effective Communications: Creating Contexts for Clarity and Meaning. New York: Allworth Press $<$ HTTPS://WWW.ACADEMIA.EDU/508000/FROM_COMMUNICATION_DESIGN_TO_ACTIVITY_DESIGN._SERVICE_ENCOUNTER _AS_CRITICAL_POINT_FOR_SYSTEM_INTERFACE_DESIGN> [ACCESSED: MĀY $\overline{15}, 2016]$.

MENICHINELLI, M. (2006). 'RETI COLLABORATIVE : IL DESIGN PER UN'AUTO-ORGANIZZAZIONE OPEN PEER-TO-PEER'. Milano: Politecnico di Milano, Facoltà del Design (III) < HTtP://www.oPenP2Pdesign.org> [AcCeSSED: May $15,2016]$.

(2011). Open P2P Design ToOlkit. How to CO-Design an Open collaborative process. <HTTP://ISSUU.COM/OPENP2PDESIGN/DOCS/OPENP2PDESIGN.TOOLKIT_PIXELACHE> [ACCESSED: MAY 15, 2016]. 
The meta-design of systems: how design, data, software enable the organizing of open, distributed and collaborative processes.

(2015). Open Meta-Design: Tools for Designing Collaborative Processes. In Empowering Users THROUGH DESIGN: INTERDisciplinARY STUdies AND COMBINED APPROACHES FOR TECHNOLOGICAL Products AND SERVices, Bihanic, D. (ED.). NeW York, NY: Springer.

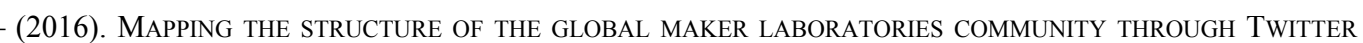
COnNections. In Twitter for Research Handbook 2015 - 2016, Levallois, C., Marchand, M., Mata, T. \& PANISSON, A. (EDS.), PP. 47-62. LyON: EMLYON PRESS < HTTP://DX.DOI.ORG/10.5281/ZENODO.44882> [ACCESSED: MAY 15, 2016].

MUNROE, R. (2009). XKCD\# 657: MOVIE NARRATIVE CHARTS. XKCD.COM. <HTTP://XKCD.COM/657/> [ACCESSED: MAY $15,2016]$.

O’REILly, T. (2005). What Is Web $2.0 \quad-\quad$ O'ReIlly Media. Oreilly.COM. <HTTP://OREILLY.COM/WEB2/ARCHIVE/WHAT-IS-WEB-20.HTML> [ACCESSED MARCH 31, 2012].

Osterwalder, A. \& Pigneur, Y. (2010). Business Model Generation: A Handbook for Visionaries, Game Changers, And Challengers. 1St ED. Wiley.

RIZZO, F. (2009). STRATEGIE DI CO-DESIGN : TEORIE, METODI E STRUMENTI PER PROGETTARE CON GLI UTENTI. MiLANO: FRANCO ANGELI.

ROMAnO, Z. (2015). OpenWear - Collaborative Clothing. In Agents of Alternatives. Re-Designing Our Realities, Fuad-Luke, A., Hirscher, A.-L. \& Moebus, K. (Eds.). Berlin: Agents of Alternatives e.V.

SANGIORGI, D. (2004). 'DESIGN DEI SERVIZI COME DESIGN DEI SISTEMI DI ATTIVITÀ : LA TEORIA DELL'ATTIVITÀ

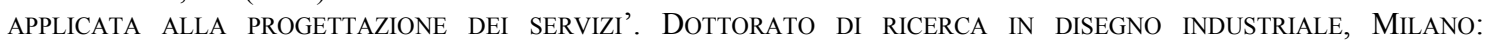
Politecnico di Milano, Dipartimento INDACO.

SCHEEL, H. VON, ROSING, M. VON, FONSECA, M. \& FOldAGER, U. (2015). Phase 1. In The Complete Business Process Handbook: Body of Knowledge from Process Modeling to BPM, Volume I, Rosing, M. vON, ScheEl, H. vON \& SCHEER, A.-W. (EDS.), PP. 429-454. WALtham, MA: Morgan Kaufmann.

SCHEEL, H. VON, ROSING, M. VON, HOVE, M. \& FONSECA, M. (2015). Phase 2: Process Concept Evolution 2.0. In The Complete Business Process Handbook: Body of Knowledge from Process Modeling to BPM, Volume I, Rosing, M. von, Scheel, H. von \& Scheer, A.-W. (EdS.), Pp. 11-36. Waltham, MA: Morgan KAUFMANN.

Shirky, C. (2008). Here Comes Everybody: The Power of Organizing Without Organizations. Penguin PRESS HC, THE.

(2011). COGNITIVE SURPLUS: HOW TECHNOLOGY MAKES CONSUMERS INTO COLLABORATORS. NEW YORK: Penguin BoOKs.

STEELE, R. D. (2012). THE OPEN-SOURCE EVERYTHING MANIFESTO: TRANSPARENCY, TRUTH, AND TRUST. BERKELEY, CALIF.: Evolver EDITIONS.

SUROWIECKI, J. (2005). THE Wisdom OF CROWDS. NEW YoRK: ANCHOR BoOKS.

TAPSCOTT, D. \& Williams, A. D. (2006). WikinOMics: How Mass Collaboration Changes Everything. NeW York: PortFolio PENGUin.

(2010). Macrowikinomics: Rebooting Business And the World. Portfolio Hardcover.

TASSI, R. (2008). 'DESIGN DELla COMUNICAZIONE E DESIGN DEI SERVIZI: PROGETTO DELLA COMUNICAZIONE PER LA FASE DI IMPLEMENTAZIONE (COMMUNICATION DESIGN AND SERVICE DESIGN: IMPLEMENTING SERVICES THROUGH communication artifacts) Politecnico di Milano'. Milano: Politecnico di Milano, Facoltà del Design (III) <HTTP://SERVICEDESIGNTOOLS.ORG/ABOUT> [ACCESSED: MAY 15, 2016].

TEDX TALKS (2012). OPEN Structures: Thomas LOMMEE AT TEDxEutropolis. <HTTPS://www.YOUTUBE.COM/WATCH?v=5FXTLOYTJRI> [ACCESSED DECEMBER 30, 2015].

WEBER, S. (2005). The Success of Open Source. Harvard University Press. 